\title{
A Modified Combination Rule for $D$ Numbers Theory
}

\author{
Ningkui Wang, ${ }^{1}$ Fuyu Liu, ${ }^{1}$ and Daijun Wei ${ }^{1,2}$ \\ ${ }^{1}$ School of Science, Hubei University for Nationalities, Enshi, Hubei 445000, China \\ ${ }^{2}$ School of Engineering, Vanderbilt University, Nashville, TN 37235, USA \\ Correspondence should be addressed to Daijun Wei; prof.wei@hotmail.com
}

Received 30 April 2016; Accepted 3 October 2016

Academic Editor: Peide Liu

Copyright (C) 2016 Ningkui Wang et al. This is an open access article distributed under the Creative Commons Attribution License, which permits unrestricted use, distribution, and reproduction in any medium, provided the original work is properly cited.

\begin{abstract}
$D$ numbers theory is an appropriate method to deal with the information of uncertainty and incompleteness when making a reasonable decision. Previous $D$ numbers theory provides a rule to combine multiple $D$ numbers. However, the commutative law is not satisfied in the rule of combining multiple $D$ numbers. In this paper, a modified method for multiple $D$ numbers combination is proposed. The proposed method defines a new function for multiple $D$ numbers combination which is mainly determined by the original value of $D$ numbers. Then the proposed combination rule is applied to environmental impact assessment (EIA); our results show that the proposed method is efficient for multiple $D$ numbers combination and it is useful when dealing with uncertainty and incompleteness.
\end{abstract}

\section{Introduction}

In the real world, it is difficult but necessary to make a comprehensive assessment to make a reasonable decision because much uncertainty and incompleteness are often involved in the assessments [1-4]. Several methods, such as probability theory $[5,6]$, fuzzy theory $[7-13]$, rough set [1417], uncertainty theory [18-20], and Dempster-Shafer theory of evidence (DST) [21-23], are widely used to deal with these problems. These methods have widely been used in kinds of fields, like supplier selection [24, 25], risk assessments [26$29]$, and so on [30,31].

The DST needs weaker conditions than the Bayesian theory of probability, it is often regarded as an extension of the Bayesian theory $[32,33]$. For the frame of discernment, which consists of mutually exclusive and collective elements, the basic probability assignment (BPA) can distribute confident degree to the power set of the frame of discernment. Furthermore, an overall assessment can be obtained by combining pairs of BPAs in the DST. Therefore, the DST has been widely applied to multiple criteria decision-making [34-44]. However, some strong hypotheses obviously exist in the DST because of the definitions of the frame of discernment and the BPA. Firstly, the elements in the frame of discernment require being mutually exclusive, but it is hard to be satisfied in the real life especially in linguistic assessments, such as the evaluation on the subjects; "good" and "very good" are two common linguistic evaluations, but they are not completely mutually exclusive so that the DST is unable to handle them. At the same time, the sum of all the BPAs must be equal to 1 . However, lacking of some professional knowledge and inadequacy judgements may lead to incompleteness everywhere in the real word. These shortcomings have limited its usage in some fields $[45,46]$.

Regarded as the generalization of DST, $D$ numbers theory is proposed by Deng $[47,48]$. It removes these hypotheses reasonably; the elements in the framework of $D$ numbers theory do not need to be mutually exclusive and incomplete assessments can also exist in $D$ numbers theory. Because $D$ numbers theory has the ability to deal with uncertainty and incompleteness, it has been used in EIA [48], failure mode and effects analysis [49], supplier selection [50], and curtain grouting efficiency assessment [51]. Nevertheless, associative property is not satisfied in the previous $D$ numbers' combination rule. In [48], Deng et al. do some work for multiple $D$ numbers combination in special circumstances. However, the associative property is not addressed in a general condition. In this paper, a modified method for multiple $D$ numbers combination is proposed. 
The remainder of this paper is organized as follows. In Section 2, preliminaries about DST and D numbers theory are described in detail. The problem of the previous $D$ numbers combination rule and the proposed method is shown in Section 3. An illustrative numerical example is presented in Section 4. Conclusions are given in Section 5.

\section{Problem Statement and Preliminaries}

2.1. Dempster-Shafer Theory. DST is proposed by Dempster and Shafer; some basic concepts are introduced as follows [21, 22].

Definition 1. Establish that $U$ is a set of mutually exclusive and collectively exhaustive elements which can be represented as follows:

$$
U=\left(e_{1}, e_{2}, e_{3}, \ldots, e_{n}\right)
$$

The power set of $U$ is denoted as $2^{U}$; any element belongs to the power set $2^{U}$ is said to be a proposition. For a frame of discernment $U$, a mass function is a mapping, which is denoted as follows:

$$
m: 2^{U} \longrightarrow[0,1]
$$

in which the following conditions are satisfied:

$$
\begin{aligned}
m(\emptyset) & =0 \\
\sum_{A \subset U} m(A) & =1,
\end{aligned}
$$

where $\emptyset$ is an empty set and $A$ is a subset of $2^{U}$; the function $m(A)$ represents how strongly the evidence supports $A$.

Definition 2 (Dempster's rule of combination). Given two BPAs $m_{1}$ and $m_{2}$, Dempster's rule of combination donated as $m=m_{1} \oplus m_{2}$ is defined as follows:

$$
m(A)= \begin{cases}\frac{1}{1-K} \sum_{B \cap C=A} m_{1}(B) m_{2}(C), & A \neq \emptyset ; \\ 0, & A=\emptyset ;\end{cases}
$$

with

$$
K=\sum_{B \cap C=\emptyset} m_{1}(B) m_{2}(C)
$$

where $A, B$, and $C$ are the elements of $2^{U}$ and $K$ is a normalization constant which means the conflict coefficient of two BPAs.

Note that Dempster's rule of combination is feasible only when $K<1$ because $K=1$ means that the two BPAs are one hundred percent conflicted. Associative property is well satisfied in Dempster's rule of combination.

2.2. D Numbers Theory. There are some strong hypotheses in DST which have limited its wide usage in some fields especially in linguistic assessments. $D$ numbers theory is proposed in $[47,48]$ and it has overcome these hypotheses. The details about $D$ numbers theory are introduced as follows.

Definition 3. Let $\Omega$ be a finite nonempty set; $D$ numbers is a mapping:

$$
D: \Omega \longrightarrow[0,1]
$$

where the following conditions are satisfied:

$$
\begin{aligned}
D(\emptyset) & =0 \\
\sum_{B \subset \Omega} D(B) & \leq 1,
\end{aligned}
$$

where $\emptyset$ is an empty set and $B$ is a subset of $\Omega$. The elements in the set $\Omega$ of $D$ numbers do not require mutual exclusiveness and the sum of the assessments can be less than 1 in $D$ numbers theory.

Suppose that five linguistic assessments "extremely poor (EP)," "poor (P)," "average (A)," "good (G)," and "very good (VG)" are used for the evaluation of a car. The framework of DST must be mutually exclusive and $D$ numbers theory providing the framework with nonexclusive hypotheses is more tallying with the actual situation. The differences of their framework of DST and D numbers are shown in Figure 1 [48]. In (7), $D$ numbers theory is acceptable for incomplete information since $\sum_{B C U} D(B) \leq 1$ which is more close to the real situation.

Definition 4. For a discrete set $\Omega=\left(b_{1}, b_{2}, b_{3}, \ldots, b_{n}\right)$, where $b_{i}$ belongs to $R$ and $b_{i} \neq b_{j}$ if $i \neq j$, for any $v_{i} \geq 0$ and $\sum_{i=1}^{n} v_{i} \leq 1$, a special form of $D$ numbers can be expressed by

$$
\begin{aligned}
& D\left(b_{1}\right)=v_{1} \\
& D\left(b_{2}\right)=v_{2} \\
& D\left(b_{3}\right)=v_{3}
\end{aligned}
$$

$$
D\left(b_{n}\right)=v_{n}
$$

or be represented simply as

$$
D=\left\{\left(b_{1}, v_{1}\right),\left(b_{2}, v_{2}\right),\left(b_{3}, v_{3}\right), \ldots,\left(b_{n}, v_{n}\right)\right\}
$$

Definition 5 ( $D$ numbers combination rule). Let $D_{1}$ and $D_{2}$ be two $D$ numbers:

$$
\begin{aligned}
& D_{1}=\left\{\left(b_{1}^{1}, v_{1}^{1}\right),\left(b_{2}^{1}, v_{2}^{1}\right),\left(b_{3}^{1}, v_{3}^{1}\right), \ldots,\left(b_{n}^{1}, v_{n}^{1}\right)\right\} \\
& D_{2}=\left\{\left(b_{1}^{2}, v_{1}^{2}\right),\left(b_{2}^{2}, v_{2}^{2}\right),\left(b_{3}^{2}, v_{3}^{2}\right), \ldots,\left(b_{n}^{2}, v_{n}^{2}\right)\right\} .
\end{aligned}
$$



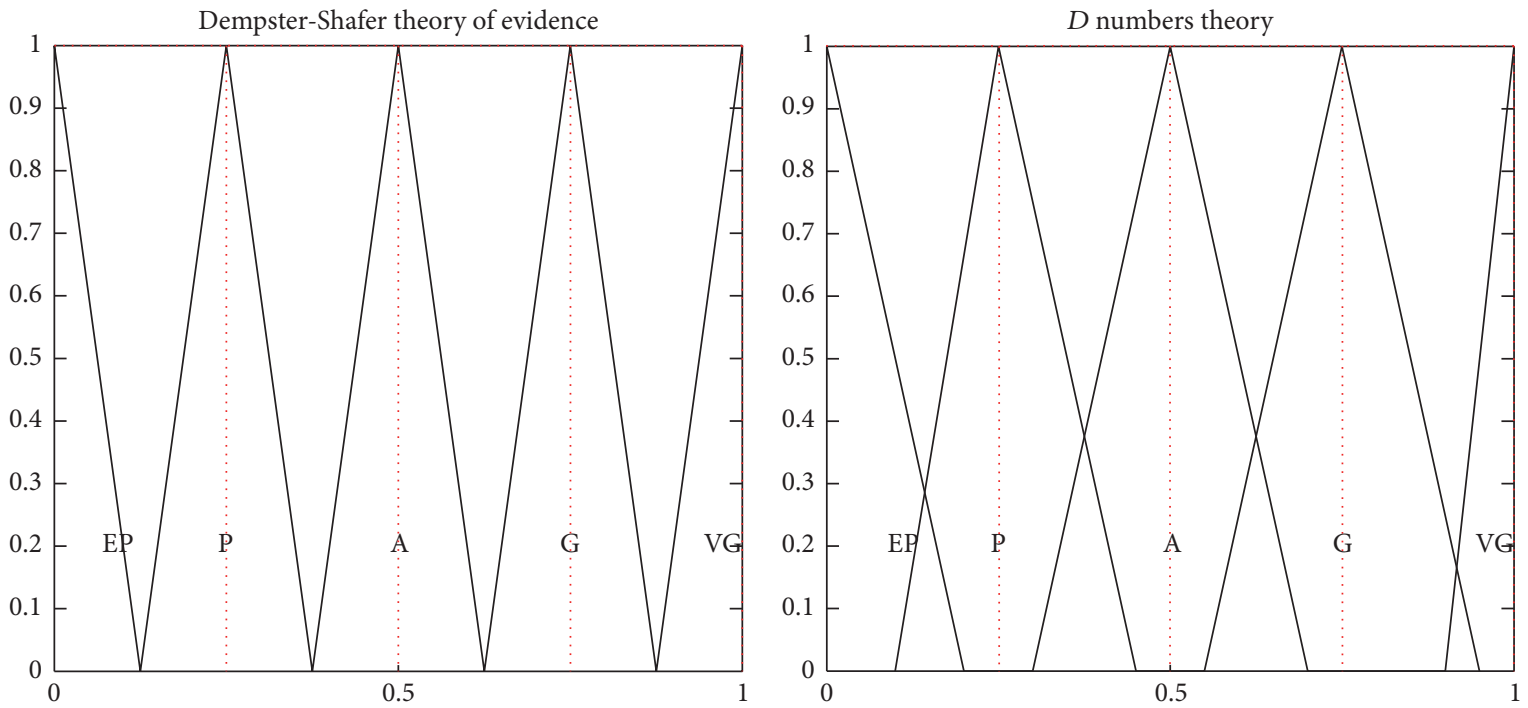

FIgURE 1: The framework of DST and $D$ numbers theory.

The combination of $D_{1}$ and $D_{2}$ denoted by $D=D_{1} \oplus D_{2}$ is defined as follows:

$$
\begin{aligned}
D(b) & =v \\
b & =\frac{\left(b_{i}^{1}+b_{j}^{2}\right)}{2} \\
v & =\frac{\left(v_{i}^{1}+v_{j}^{2}\right)}{2 \times c} \\
C & = \begin{cases}\sum_{j=1}^{m} \sum_{i=1}^{n}\left(\frac{v_{i}^{1}+v_{j}^{2}}{2}\right) & \sum_{i=1}^{n} v_{i}^{1}=1, \sum_{i=1}^{m} v_{j}^{1}=1 ; \\
\sum_{j=1}^{m} \sum_{i=1}^{n}\left(\frac{v_{i}^{1}+v_{j}^{2}}{2}\right)+\sum_{j=1}^{m}\left(\frac{v_{c}^{1}+v_{j}^{2}}{2}\right) & \sum_{i=1}^{n} v_{i}^{1}<1, \sum_{i=1}^{m} v_{j}^{1}=1 ; \\
\sum_{j=1}^{m} \sum_{i=1}^{n}\left(\frac{v_{i}^{1}+v_{j}^{2}}{2}\right)+\sum_{i=1}^{n}\left(\frac{v_{i}^{1}+v_{c}^{2}}{2}\right) & \sum_{i=1}^{n} v_{i}^{1}=1, \sum_{i=1}^{m} v_{j}^{1}<1 ; \\
\sum_{j=1}^{m} \sum_{i=1}^{n}\left(\frac{v_{i}^{1}+v_{j}^{2}}{2}\right)+\sum_{j=1}^{m}\left(\frac{v_{c}^{1}+v_{j}^{2}}{2}\right)+\sum_{i=1}^{n}\left(\frac{v_{i}^{1}+v_{c}^{2}}{2}\right) & \sum_{i=1}^{n} v_{i}^{1}<1, \sum_{i=1}^{m} v_{j}^{1}<1,\end{cases}
\end{aligned}
$$

where $v_{c}^{1}=1-\sum_{i=1}^{n} v_{i}^{1}$ and $v_{c}^{2}=1-\sum_{j=1}^{m} v_{j}^{2}, m$ and $n$ are the assessment numbers in each $D$ number, and the superscripts in above equations are not the exponent but the order of the $D$ numbers.

Definition 6 ( $D$ numbers' integration). For given $D$ numbers, the overall assessments can be calculated as follows:

$$
I(D)=\sum_{i=1}^{n} b_{i} v_{i}
$$

\section{Proposed Method}

3.1. Problem of Existing D Numbers Combination Rule. It has to be pointed out that the associative property is not satisfied in the previous $D$ numbers combination rule; that is to say that the sequence of multiple $D$ numbers has great effects on the final results when they get combined. As can be seen in the previous $D$ numbers combination rule, $b=\left(b_{i}^{1}+b_{j}^{2}\right) / 2$ and $v=\left(v_{i}^{1}+v_{j}^{2}\right) /(2 \times c)$; when three $D$ numbers $D_{1}, D_{2}$, and 
$D_{3}$ get combined, the $b$ and $v$ of the combined results should be

$$
\begin{aligned}
& b=\frac{\left(b_{1}+b_{2}\right) / 2+b_{3}}{2} \\
& v=\frac{\left(v_{1}+v_{2}\right) / 2 c_{1}+v_{3}}{2 c_{2}}
\end{aligned}
$$

which means that the third $D$ number $D_{3}$ has more effect on the final results. The associative property is not satisfied in the rule of combining multiple $D$ numbers. Meanwhile, the calculated quantity may increase by multiplication with the evaluation grades increasing in $D$ numbers theory.

Therefore, a method, with which to solve the EIA, is proposed [48]. In that method, an order variable for multiple $D$ numbers combination is given. As each $D$ number is given by a knowledgeable expert from different cultural or educational backgrounds, so all of them will be evaluated in different weights in the decision-making system. The higher the weight is, the more credible the expert should be. For example, three $D$ numbers shown below, $\omega_{1}, \omega_{2}$, and $\omega_{3}$, are the weights of the $D$ numbers separately:

$$
\begin{aligned}
& D_{1}=\{(0,0.6),(1,0.4)\}, \\
& \omega_{1}=0.3 \\
& D_{2}=\{(0,0.5),(1,0.5)\}, \\
& \omega_{2}=0.5 \\
& D_{3}=\{(0,0.2),(1,0.8)\}, \\
& \omega_{3}=0.2 .
\end{aligned}
$$

Since $\omega_{3}<\omega_{1}<\omega_{2}$, the combination sequence is $\left(D_{3} \oplus\right.$ $\left.D_{1}\right) \oplus D_{2}$. If experts' weights are set to be equal, all possible combination results need to be calculated and the highest value of $D$ numbers integration is the best combination result. However, it is so hard to decide the weight of every decisionmaker and deciding the weight will always involve human subjective judgements. What is more, when the weights are set to be equal, all possible combination results will have enormous computational complexity.

3.2. Unconfident-Confident Combination Rule of D Numbers. In this section, a new combination sequence for $D$ numbers theory is proposed. The proposed combination rule includes two independent parts, which are "unconfident $D$ numbers combination rule" and "confident $D$ numbers combination rule," respectively. For given $D$ number $D_{i}=\left\{\left(b_{i}, v_{i}\right)\right\}$ $(i=1,2, \ldots, n), b_{i}$ is the assessment grade the decisionmakers made on the decision-making problems and $v_{i}$ is the confident value to the assessment grade $b_{i}$. The value of $v_{i}$ being more close to 1 means that decision-maker is more confident about the assessment grade. Therefore, the proposed method is given as follows.

Definition 7 (unconfident $D$ numbers combination rule). For given $D$ numbers, if they are different from each other, the maximum value of $v_{i}$ should be calculated firstly. Suppose $D_{1}, D_{2}, \ldots, D_{n}$ are $n D$ numbers:

$$
\begin{gathered}
D_{1}=\left\{\left(b_{1}^{1}, v_{1}^{1}\right),\left(b_{2}^{1}, v_{2}^{1}\right),\left(b_{3}^{1}, v_{3}^{1}\right), \ldots,\left(b_{n}^{1}, v_{n}^{1}\right)\right\} \\
D_{2}=\left\{\left(b_{1}^{2}, v_{1}^{2}\right),\left(b_{2}^{2}, v_{2}^{2}\right),\left(b_{3}^{2}, v_{3}^{2}\right), \ldots,\left(b_{n}^{2}, v_{n}^{2}\right)\right\} \\
\vdots \\
D_{n}=\left\{\left(b_{1}^{n}, v_{1}^{n}\right),\left(b_{2}^{n}, v_{2}^{n}\right),\left(b_{3}^{n}, v_{3}^{n}\right), \ldots,\left(b_{n}^{n}, v_{n}^{n}\right)\right\},
\end{gathered}
$$

where

$$
\begin{gathered}
V_{1 \max }=\max \left\{v_{1}^{1}, v_{2}^{1}, v_{3}^{1}, \ldots, v_{n}^{1}\right\} \\
V_{2 \max }=\max \left\{v_{1}^{2}, v_{2}^{2}, v_{3}^{2}, \ldots, v_{n}^{2}\right\} \\
\vdots \\
V_{n \max }=\max \left\{v_{1}^{n}, v_{2}^{n}, v_{3}^{n}, \ldots, v_{n}^{n}\right\} .
\end{gathered}
$$

Then the combination operation of multiple $D$ numbers is a mapping $f_{D}$, such that

$$
\begin{aligned}
f_{D} & \left(D_{1}, D_{2}, D_{3}, \ldots, D_{n}\right) \\
& =\left[\cdots\left[\left[D_{i} \oplus D_{j}\right] \oplus D_{k}\right] \cdots\right],
\end{aligned}
$$

where $V_{i \max }>V_{j \max }>V_{k \max }$ in unconfident $D$ numbers combination rule and $V_{i \max }, V_{j \max }$, and $V_{k \max }$ are corresponding to $D_{i}, D_{j}$, and $D_{k}$.

In the unconfident $D$ numbers combination rule, if some assessments are completely the same, then these assessments should be combined at the first step. Meanwhile, the combinatorial results should be the same to each of the $D$ numbers since the same assessments indicate that all the experts have the same opinions on the object. For example, $D_{i}(i=$ $1,2,3, \ldots, n)$ are completely the same.

$$
\begin{gathered}
D_{1}=\left\{\left(b_{1}^{1}, v_{1}^{1}\right),\left(b_{2}^{1}, v_{2}^{1}\right), \ldots,\left(b_{i}^{1}, v_{i}^{1}\right), \ldots,\left(b_{n}^{1}, v_{n}^{1}\right)\right\}, \\
D_{2}=\left\{\left(b_{1}^{2}, v_{1}^{2}\right),\left(b_{2}^{2}, v_{2}^{2}\right), \ldots,\left(b_{j}^{2}, v_{j}^{2}\right), \ldots,\left(b_{n}^{2}, v_{n}^{2}\right)\right\}, \\
\vdots \\
D_{n}=\left\{\left(b_{1}^{n}, v_{1}^{n}\right),\left(b_{2}^{n}, v_{2}^{n}\right), \ldots,\left(b_{j}^{n}, v_{j}^{n}\right), \ldots,\left(b_{n}^{n}, v_{n}^{n}\right)\right\},
\end{gathered}
$$

where $b_{j}^{i}(i=1,2, \ldots, n)$ are of the same value and $v_{j}^{i}(i=$ $1,2, \ldots, n)$ are the same confident value as their assessment correspondingly separately. When the $n D$ numbers get combined, the final result $D$ should be the same as each of them; that is to say,

$$
D=D_{1} \oplus D_{2} \oplus \cdots \oplus D_{n}=D_{1}=D_{2}=\cdots=D_{n} .
$$

In (19), if the maximum $V_{i}$ are of the same value, the better average assessment grades will be combined ahead of the lower average evaluated grades. That is to say, the 
order of combination is according to the value of average $b_{i}$ from largest to smallest. The higher average assessment means evaluating it more positively and the lower average assessment means evaluating it more negatively.

In order to illustrate the law of combination of $D$ numbers, for example, the assessment on one project is conducted. $D_{1}, D_{2}, D_{3}, D_{4}$, and $D_{5}$ are five $D$ numbers given by five experts from different fields:

$$
\begin{aligned}
D_{1} & =\{(0,0.3),(1,0.5)\}, \\
V_{1 \max } & =0.5 \\
D_{2} & =\{(1,0.5),(2,0.4)\}, \\
V_{2 \max } & =0.5 \\
D_{3} & =\{(0,0.6),(1,0.4)\}, \\
V_{3 \max } & =0.6 \\
D_{4} & =\{(1,0.8),(2,0.2)\}, \\
V_{4 \max } & =0.8 \\
D_{5} & =\{(1,0.8),(2,0.2)\}, \\
V_{5 \max } & =0.8 .
\end{aligned}
$$

As $D_{4}$ and $D_{5}$ are completely the same assessments, we have $D_{45}=D_{4} \oplus D_{5}=D_{4}=D_{5}$. Then the combined result will be combined with the left $D$ numbers $D_{1}, D_{2}$, and $D_{3}$, as $V_{3 \max }$ is the biggest value of the three $D$ numbers. So $D_{45}$ will combine with $D_{3}$ at the second step. As $V_{1 \max }$ and $V_{2 \max }$ are of the same value, the better average value of $b$ will be chosen firstly. In $D_{1}$, the value of average $b$ is 0.5 . In $D_{2}$, the value of average $b$ is 1.5 . Therefore, $D_{2}$ is combined at the third step. The final combined result should be

$$
D=D_{4} \oplus D_{5} \oplus D_{3} \oplus D_{2} \oplus D_{1} .
$$

As the value of $v$ shows the confident degree to the assessments, according to (13) and (14), the smaller the value of $V_{i}$ is, the bigger the weight of the combination of $V_{i}$ will be. The order of combination is from maximum value $V$ to minimum value $V$. Thus, it is called "unconfident $D$ numbers combination rule."

Meanwhile, another $D$ numbers combination rule called "confident $D$ numbers combination rule" is used accompanying "unconfident $D$ numbers combination rule." In confident $D$ numbers combination rule, the first step is the same as the unconfident method and all the same assessments should be combined with the same results as each of the $D$ numbers.

Definition 8 (confident $D$ numbers combination rule). In (19), the lower value of " $V$ " will be chosen firstly; that is to say, in confident combination rule,

$$
\begin{aligned}
f_{D} & \left(D_{1}, D_{2}, D_{3}, \ldots, D_{n}\right) \\
& =\left[\cdots\left[\left[D_{i} \oplus D_{j}\right] \oplus D_{k}\right] \cdots\right],
\end{aligned}
$$

where $V_{i \max }<V_{j \max }<V_{k \max }$ and $V_{i \max }$ and $V_{j \max }$ and $V_{k \max }$ are corresponding to $D_{i}, D_{j}$, and $D_{k}$.
The confident $D$ numbers combination rule is contrary to the unconfident combination rule. Then when minimum values are of the same value, the lower average assessment grade will be combined ahead of the better average evaluated grade.

\section{Examples and Applications}

In this section, the proposed method is adopted to EIA. EIA usually contains four steps. Firstly the hierarchical structure model for assessment needs to be established, the second step is the assessment for each environmental impact factor, the third step is the calculation of all the evaluated factors, and the last step is to rank the entire projects. In an EIA example, the assessment on the impact of four projects for the conservation of the area of Rupa Tal is taken as follows $[52,53]$.

Project 1 . Keep it the way it is and do not make changes. The lake is disappearing and a small gorge is formed to control the streams because the present sedimentation is still continuing.

Project 2. A high retaining dam is created to raise the overall water level along the southern edge and the in-lake areas created by sedimentation over the last few decades would be overflowed because of the build of retaining dam.

Project 3. Between two precipices, a smaller high dam is built. This dam is smaller than that built in project 2 but has similar upstream effects.

Project 4. A single large sedimentation reservoir is in the upstream area, or a series of smaller retaining walls which would be used to form a sedimentation cascade. The water area may remain intact by this project.

In order to assess these four projects, each factor has some primary subfactors which is shown in Table 1 in detail; every subfactor has different influences on the assessment of the projects.

Second the calculation of the assessment should be done. Nevertheless most of the assessments are represented by linguistic grades like "good" and "poor" and " $A$," " $B$," and " $C$," and so on. First of all, translating such a kind of assessment into numerical grade is necessary. In the existing world, a seven-point scale and five grades are presented [54]. In this method, $3,2,1,0,-1,-2$, and -3 represent "very good" to "moderate" to "very bad". The original grades are represented by the letters " $A$," " $B$," " $C$," and so on [52]. In [48], the grade is translated into numerical and shown in Table 2.

From Table 2, the assessment $E$ means major positive impacts and the numerical number is 5 . The assessment $N$ means no impact; we translate it into 0 . Then the $D$ numbers are obtained from the assessment of experts. For example, when ten experts give the assessments for the conservation of Rupa Tal, six experts believe it is major positive impacts and other four evaluate it to be moderately positive impact; then $D$ numbers should be $\{(5,0.6),(3,0.4)\}$. If five experts assess it to be positive impact while four experts evaluate it to be no impact, the remaining expert does not give any evaluation 
TABLE 1: The meanings of factors and subfactors in EIA in literature [52].

\begin{tabular}{|c|c|}
\hline Factor & Subfactor \\
\hline \multicolumn{2}{|c|}{ Physical/chemical (P/C) } \\
\hline $\mathrm{P} / \mathrm{C}_{1}$ & The impacts of lake water volume \\
\hline $\mathrm{P} / \mathrm{C}_{2}$ & The impacts of the lake sedimentation \\
\hline $\mathrm{P} / \mathrm{C}_{3}$ & The impacts of crop and grazing areas \\
\hline \multicolumn{2}{|c|}{ Biological/ecological (B/E) } \\
\hline $\mathrm{B} / \mathrm{E}_{1}$ & The impacts of lake fisheries \\
\hline $\mathrm{B} / \mathrm{E}_{2}$ & The impacts of biodiversity \\
\hline $\mathrm{B} / \mathrm{E}_{3}$ & The impacts of primary production \\
\hline $\mathrm{B} / \mathrm{E}_{4}$ & The impacts of aquatic macrophytes \\
\hline $\mathrm{B} / \mathrm{E}_{5}$ & The impacts of disease vector populations \\
\hline \multicolumn{2}{|c|}{ Sociological/cultural (S/C) } \\
\hline $\mathrm{S} / \mathrm{C}_{1}$ & The loss of housing \\
\hline $\mathrm{S} / \mathrm{C}_{2}$ & The loss of shops/public buildings \\
\hline $\mathrm{S} / \mathrm{C}_{3}$ & The impacts of accessing routes \\
\hline $\mathrm{S} / \mathrm{C}_{4}$ & The impacts induced by changes of tourism patterns \\
\hline $\mathrm{S} / \mathrm{C}_{5}$ & The impacts of water supplies \\
\hline $\mathrm{S} / \mathrm{C}_{6}$ & The impacts of diet/nutrition \\
\hline $\mathrm{S} / \mathrm{C}_{7}$ & The impacts of aesthetic landscapes \\
\hline $\mathrm{S} / \mathrm{C}_{8}$ & The impacts of water/vector borne disease \\
\hline $\mathrm{S} / \mathrm{C}_{9}$ & The impacts of upstream quality of life \\
\hline $\mathrm{S} / \mathrm{C}_{10}$ & The impacts of downstream quality of life \\
\hline \multicolumn{2}{|c|}{ Economic/operational (E/O) } \\
\hline $\mathrm{E} / \mathrm{O}_{1}$ & The impacts of crop-generated incomes \\
\hline $\mathrm{E} / \mathrm{O}_{2}$ & The impacts of fishery generated incomes \\
\hline $\mathrm{E} / \mathrm{O}_{3}$ & The convenience of operation and maintenance of option \\
\hline $\mathrm{E} / \mathrm{O}_{4}$ & The cost of operation and maintenance of option \\
\hline $\mathrm{E} / \mathrm{O}_{5}$ & The cost of resettlement/compensation for land loss \\
\hline $\mathrm{E} / \mathrm{O}_{6}$ & The cost of rehabilitation and restoration of shops \\
\hline $\mathrm{E} / \mathrm{O}_{7}$ & The cost of restoration of accessing routes \\
\hline $\mathrm{E} / \mathrm{O}_{8}$ & The impacts of tourism-generated incomes \\
\hline
\end{tabular}

TABLE 2: An assessment standard for EIA.

\begin{tabular}{lcc}
\hline $\begin{array}{l}\text { Assessment } \\
\text { grade }\end{array}$ & Numerical rating & Description \\
\hline$E$ & 5 & Major positive impact \\
$D$ & 4 & Signification positive impact \\
$C$ & 3 & Moderately positive impact \\
$B$ & 2 & Positive impact \\
$A$ & 1 & Slight impact \\
$N$ & 0 & No impact \\
$-A$ & -1 & Slightly negative impact \\
$-B$ & -2 & Negative impact \\
$-C$ & -3 & Moderately negative impact \\
$-D$ & -4 & Significant negative impact \\
$-E$ & -5 & Major negative impact \\
\hline
\end{tabular}

because of lacking information; the $D$ numbers can be $\{(3,0.5),(0,0.4)\}$; this kind of information is incomplete. The assessment matrix for project 1 and project 2 and project 3 and project 4 are shown in Tables 3 and 4, respectively.
The overall assessment for different projects is calculated via unconfident and confident $D$ numbers combination rule, respectively. For example, in unconfident $D$ numbers combination rule, for the evaluation of project 4 , the environmental factors are biological and ecological. To the subfactors $B / E_{1}$, $\mathrm{B} / \mathrm{E}_{2}, \mathrm{~B} / \mathrm{E}_{3}$, and $\mathrm{B} / \mathrm{E}_{4}$, all the assessments are $\{(0,1)\}$; to subfactor $B / E_{5}$, the assessment is $\{(-1,0.4),(0,0.5)\}$. Firstly, the same assessment should be combined:

$$
\begin{aligned}
& \{(0,1)\} \oplus\{(0,1)\} \oplus\{(0,1)\} \oplus\{(0,1)\} \oplus\{(0,1)\} \\
& \quad=\{(0,1)\} .
\end{aligned}
$$

Secondly, the combined result $\{(0,1)\}$ needs to be fused with $\mathrm{B} / \mathrm{E}_{5}$ :

$$
\begin{array}{r}
\{(-1,0.4),(0,0.5)\} \oplus\{(0,1)\} \\
=\left\{\left(0.5, \frac{1.4}{4}\right),\left(0, \frac{1.5}{4}\right)\right\} .
\end{array}
$$

Then, all assessments are combined by same process. 
TABLE 3: Assessment matrix of environment impact factors for projects 1 and 2 [52].

\begin{tabular}{|c|c|c|}
\hline Environmental factors & Project 1 & Project 2 \\
\hline \multicolumn{3}{|l|}{ Physical/chemical } \\
\hline $\mathrm{P} / \mathrm{C}_{1}$ & $\{(-4,0.3),(-3,0.7)\}$ & $\{(1,0.1),(2,0.9)\}$ \\
\hline $\mathrm{P} / \mathrm{C}_{2}$ & $\{(-2,0.8),(-1,0.2)\}$ & $\{(1,0.1),(2,0.85)\}$ \\
\hline $\mathrm{P} / \mathrm{C}_{3}$ & $\{2,0.45),(3,0.35)\}$ & $\{(-3,0.2),(-2,0.8)\}$ \\
\hline \multicolumn{3}{|l|}{ Biological/ecological } \\
\hline $\mathrm{B} / \mathrm{E}_{1}$ & $\{(-3,0.5),(-2,0.4)\}$ & \\
\hline $\mathrm{B} / \mathrm{E}_{2}$ & $\{(-2,0.5),(-1,0.5)\}$ & $\{(-1,1.0)\}$ \\
\hline $\mathrm{B} / \mathrm{E}_{3}$ & $\{(-2,1.0)\}$ & $\{(-2,1.0)\}$ \\
\hline $\mathrm{B} / \mathrm{E}_{4}$ & $\{(-2,1.0)\}$ & $\{(-2,1.0)\}$ \\
\hline $\mathrm{B} / \mathrm{E}_{5}$ & & $\{(1,1.0)\}$ \\
\hline \multicolumn{3}{|l|}{ Sociological/culture S/C } \\
\hline $\mathrm{S} / \mathrm{C}_{1}$ & $\{(0,1.0)\}$ & $\{(-1,1.0)\}$ \\
\hline $\mathrm{S} / \mathrm{C}_{2}$ & $\{(0,1.0)\}$ & $\{(-1,0.65),(0,0.03)\}$ \\
\hline $\mathrm{S} / \mathrm{C}_{3}$ & $\{(1,0.5),(2,0.5)\}$ & $\{(-1,1.0)\}$ \\
\hline $\mathrm{S} / \mathrm{C}_{4}$ & $\{(-2,0.2),(1,0.8)\}$ & $\{(2,0.8),(3,0.2)\}$ \\
\hline $\mathrm{S} / \mathrm{C}_{5}$ & $\{(-2,0.3),(1,0.7)\}$ & $\{(3,1.0)\}$ \\
\hline $\mathrm{S} / \mathrm{C}_{6}$ & $\{(0,1.0)\}$ & $\{(1,0.8),(2,0.2)\}$ \\
\hline $\mathrm{S} / \mathrm{C}_{7}$ & $\{(-2,1.0)\}$ & $\{(2,1.0)\}$ \\
\hline $\mathrm{S} / \mathrm{C}_{8}$ & $\{(1,0.5),(2,0.3)\}$ & $\{(-1,1.0)\}$ \\
\hline $\mathrm{S} / \mathrm{C}_{9}$ & $\{(0,1.0)\}$ & $\{(1,1.0)\}$ \\
\hline $\mathrm{S} / \mathrm{C}_{10}$ & $\{(-1,1.0)\}$ & $\{(2,1.0)\}$ \\
\hline \multicolumn{3}{|l|}{ Economical/operational } \\
\hline $\mathrm{E} / \mathrm{O}_{1}$ & $\{(2,0.8)\}$ & $\{(-1,1.0)\}$ \\
\hline $\mathrm{E} / \mathrm{O}_{2}$ & $\{(-2,1.0)\}$ & $\{(2,1.0)\}$ \\
\hline $\mathrm{E} / \mathrm{O}_{3}$ & $\{(0,1.0)\}$ & $\{(-1,1.0)\}$ \\
\hline $\mathrm{E} / \mathrm{O}_{4}$ & $\{(0,1.0)\}$ & $\{(-1,1.0)\}$ \\
\hline $\mathrm{E} / \mathrm{O}_{5}$ & $\{(0,1.0)\}$ & $\{(-1,1.0)\}$ \\
\hline $\mathrm{E} / \mathrm{O}_{6}$ & $\{(0,1.0)\}$ & $\{(-1,1.0)\}$ \\
\hline $\mathrm{E} / \mathrm{O}_{7}$ & $\{(0,1.0)\}$ & $\{(-1,1.0)\}$ \\
\hline $\mathrm{E} / \mathrm{O}_{8}$ & $\{(-1,1.0)\}$ & $\{(3,0.7)\}$ \\
\hline
\end{tabular}

Lastly, by (15), the last score can be calculated and the example above is taken into consideration:

$$
I(D)=0.5 \times \frac{1.4}{4}+0 \times \frac{1.5}{4}=0.175 .
$$

The final results and ranking are obtained and shown in Table 5 by unconfident and confident $D$ numbers combination rule.

From Table 5, the final ranking is project $2>$ project $3>$ project $4>$ project 1 by using unconfident $D$ numbers combination rule. According to confident $D$ numbers combination rule, the ranking is project $3>$ project $2>$ project $4>$ project 1. The results by the evidential reasoning approach (shortly ER approach) [52] and previous $D$ numbers combination rule (shortly previous $D$ method) [48] are shown in Table 6. From Tables 5 and 6, our results of unconfident $D$ numbers combination rule are the same as risk-taking method [52]. The results of confident $D$ numbers combination rule are the same as decision-optimistic method in [48]. Meanwhile, project 1 is always the worst choice for all methods. In ER approach, the best choice is project 2 or project 4 . In previous
$D$ method, the best choice is project 3 or project 4 . In our method, the best choice is project 2 and project 3; there is the same option for these researches. Furthermore, the unconfident-confident combination rule of $D$ numbers is only determined by the original data of $D$ numbers, any other information about $D$ numbers is no longer needed.

\section{Conclusions}

How to deal with uncertain and incomplete information to make decisions is an open issue. $D$ numbers theory, which is an extension of DST, has the ability to combine multiple evidence and is wildly used to deal with uncertain and incomplete information problems. However, the associative property for multiple $D$ numbers combination is not satisfied. In this paper, A modified method for multiple $D$ numbers combination denoted as unconfident-confident combination rule is proposed. In our method, the combination rule only depends on the values of $D$ numbers themselves. The proposed method is applied to EIA and the numerical results indicate the effectiveness of the proposed method. 
TABLE 4: Assessment matrix of environmental impact factors for projects 3 and 4 [52].

\begin{tabular}{|c|c|c|}
\hline Environmental factors & Project 3 & Project 4 \\
\hline \multicolumn{3}{|l|}{ Physical/chemical } \\
\hline $\mathrm{P} / \mathrm{C}_{1}$ & $\{(2,0.8),(3,0.2)\}$ & $\{(0,1)\}$ \\
\hline $\mathrm{P} / \mathrm{C}_{2}$ & $\{(-1,0.85),(3,0.15)\}$ & $\{(1,0.3),(2,0.7)\}$ \\
\hline $\mathrm{P} / \mathrm{C}_{3}$ & $\{(0,0.5),(1,0.5)\}$ & $\{(0,1)\}$ \\
\hline \multicolumn{3}{|l|}{ Biological/ecological } \\
\hline $\mathrm{B} / \mathrm{E}_{1}$ & $\{(0,0.2),(1,0.8)\}$ & $\{(0,1)\}$ \\
\hline $\mathrm{B} / \mathrm{E}_{2}$ & $\{(-2,0.8),(-1,0.1)\}$ & $\{(0,1)\}$ \\
\hline $\mathrm{B} / \mathrm{E}_{3}$ & $\{(-1,1.0)\}$ & $\{(0,1)\}$ \\
\hline $\mathrm{B} / \mathrm{E}_{4}$ & $\{(-1,1.0)\}$ & $\{(0,1)\}$ \\
\hline $\mathrm{B} / \mathrm{E}_{5}$ & $\{(1,1.0)\}$ & $\{(-1,0.4),(0,0.5)\}$ \\
\hline \multicolumn{3}{|l|}{ Sociological/culture S/C } \\
\hline $\mathrm{S} / \mathrm{C}_{1}$ & $\{(-1,1.0)\}$ & $\{(0,1.0)\}$ \\
\hline $\mathrm{S} / \mathrm{C}_{2}$ & $\{(-1,1.0)\}$ & $\{(0,1.0)\}$ \\
\hline $\mathrm{S} / \mathrm{C}_{3}$ & & $\{(0,1.0)\}$ \\
\hline $\mathrm{S} / \mathrm{C}_{4}$ & $\{(1,1.0)\}$ & $\{(0,1.0)\}$ \\
\hline $\mathrm{S} / \mathrm{C}_{5}$ & $\{(1,1.0)\}$ & $\{(1,0.8)\}$ \\
\hline $\mathrm{S} / \mathrm{C}_{6}$ & $\{(1,0.5),(2,0.5)\}$ & $\{(0,1.0)\}$ \\
\hline $\mathrm{S} / \mathrm{C}_{7}$ & $\{(-1,0.85),(3,0.15)\}$ & $\{(0,1.0)\}$ \\
\hline $\mathrm{S} / \mathrm{C}_{8}$ & $\{(1,1.0)\}$ & $\{(-1,1.0)\}$ \\
\hline $\mathrm{S} / \mathrm{C}_{9}$ & $\{(0,0.2),(1,0.7)\}$ & $\{(-1,1.0)\}$ \\
\hline $\mathrm{S} / \mathrm{C}_{10}$ & $\{(-2,0.8),(-1,0.2)\}$ & $\{(0,1.0)\}$ \\
\hline \multicolumn{3}{|l|}{ Economical/operational } \\
\hline $\mathrm{E} / \mathrm{O}_{1}$ & $\{(-2,0.9)\}$ & $\{(0,1.0)\}$ \\
\hline $\mathrm{E} / \mathrm{O}_{2}$ & $\{(0,1.0)\}$ & $\{(0,1.0)\}$ \\
\hline $\mathrm{E} / \mathrm{O}_{3}$ & $\{(-1,1.0)\}$ & $\{(-2,1.0)\}$ \\
\hline $\mathrm{E} / \mathrm{O}_{4}$ & $\{(-1,1.0)\}$ & $\{(-2,1.0)\}$ \\
\hline $\mathrm{E} / \mathrm{O}_{5}$ & $\{(-1,1.0)\}$ & $\{(0,1.0)\}$ \\
\hline $\mathrm{E} / \mathrm{O}_{6}$ & $\{(-1,1.0)\}$ & $\{(0,1.0)\}$ \\
\hline $\mathrm{E} / \mathrm{O}_{7}$ & $\{(-1,1.0)\}$ & $\{(0,1.0)\}$ \\
\hline $\mathrm{E} / \mathrm{O}_{8}$ & $\{(1,1.0)\}$ & $\{(0,1.0)\}$ \\
\hline
\end{tabular}

TABLE 5: Overall environmental impacts and ranking of each project.

\begin{tabular}{lcc}
\hline Assessment grade & Impact rating & Ranking \\
\hline Unconfident method & & \\
Project 1 & -0.18720 & 4 \\
Project 2 & 0.09550 & 1 \\
Project 3 & 0.04909 & 2 \\
Project 4 & -0.03760 & 3 \\
Confident method & & \\
Project 1 & -0.3453 & 4 \\
Project 2 & -0.0444 & 2 \\
Project 3 & 0.2984 & 1 \\
Project 4 & -0.29727 & 3 \\
\hline
\end{tabular}

In the future, more work should be done for multiple $D$ numbers combination. $D$ numbers theory is regarded as the generation of DST; many mathematical theorems including the associative property are satisfied in DST. It
TABLE 6: Overall environmental impacts and ranking of each project.

\begin{tabular}{|c|c|}
\hline Method & Ranking \\
\hline \multicolumn{2}{|l|}{ ER approach } \\
\hline Risk-neutral & $\begin{array}{c}\text { Project } 2>\text { project } 4> \\
\text { project } 3>\text { project } 1\end{array}$ \\
\hline Risk-taking & $\begin{array}{c}\text { Project } 2>\text { project } 3> \\
\text { project } 4>\text { project } 1\end{array}$ \\
\hline Risk-average & $\begin{array}{c}\text { Project } 4>\text { project } 2> \\
\text { project } 3>\text { project } 1\end{array}$ \\
\hline \multicolumn{2}{|l|}{$D$ method } \\
\hline Decision-optimistic & $\begin{array}{c}\text { Project } 3>\text { project } 2> \\
\text { project } 4>\text { project } 1\end{array}$ \\
\hline Decision-pessimistic & $\begin{array}{c}\text { Project } 4>\text { project } 2> \\
\text { project } 3>\text { project } 1\end{array}$ \\
\hline
\end{tabular}

is reasonable for us to believe that the associative property should be satisfied in $D$ numbers theory. More attempts will be made to find out the solution in which many mathematical 
theorems are satisfied in the multiple $D$ numbers combination rule. Meanwhile, $D$ numbers theory should be put into applications in more fields to deal with uncertainty and incompleteness, like risk evaluation and so on.

\section{Competing Interests}

The authors declare that there are no competing interests regarding the publication of this article.

\section{Acknowledgments}

The work is partially supported by China Scholar Council, National Natural Science Foundation of China (Grants nos. 61364030 and 11365008), the Funding Project of Educational Commission of Hubei Province of China (Grant no. D20151902), the Doctoral Scientific Research Foundation of Hubei University for Nationalities (Grant no. MY2014b003), the Training Programs of Innovation and Entrepreneurship for Undergraduates of Hubei Province (Grant no. 201410517018).

\section{References}

[1] P. Liu and X. Yu, "2-Dimension uncertain linguistic power generalized weighted aggregation operator and its application in multiple attribute group decision making," Knowledge-Based Systems, vol. 57, pp. 69-80, 2014.

[2] D. Yu, "Multiattribute decision making based on intuitionistic fuzzy interaction average operators: a comparison," International Transactions in Operational Research, vol. 22, no. 6, pp. 1017-1032, 2015.

[3] P. Liu and L. Shi, "The generalized hybrid weighted average operator based on interval neutrosophic hesitant set and its application to multiple attribute decision making," Neural Computing \& Applications, vol. 26, no. 2, pp. 457-471, 2014.

[4] W. Jiang, C. Xie, M. Zhuang, Y. Shou, and Y. Tang, "Sensor data fusion with $\mathrm{Z}$-numbers and its application in fault diagnosis," Sensors, vol. 16, no. 9, p. 1509, 2016.

[5] E. T. Jaynes, Probability Theory: The Logic of Science, Cambridge University Press, 2003.

[6] A. F. Peressini, "Imprecise probability and chance," Erkenntnis, vol. 81, no. 3, pp. 561-586, 2016.

[7] H.-M. Lee, "Group decision making using fuzzy sets theory for evaluating the rate of aggregative risk in software development," Fuzzy Sets \& Systems, vol. 80, no. 3, pp. 261-271, 1996.

[8] P. Liu and F. Jin, "A multi-attribute group decision-making method based on weighted geometric aggregation operators of interval-valued trapezoidal fuzzy numbers," Applied Mathematical Modelling. Simulation and Computation for Engineering and Environmental Systems, vol. 36, no. 6, pp. 2498-2509, 2012.

[9] Q. Li, "A novel Likert scale based on fuzzy sets theory," Expert Systems with Applications, vol. 40, no. 5, pp. 1609-1618, 2013.

[10] W. Jiang, Y. Luo, X.-Y. Qin, and J. Zhan, "An improved method to rank generalized fuzzy numbers with different left heights and right heights," Journal of Intelligent and Fuzzy Systems, vol. 28, no. 5, pp. 2343-2355, 2015.

[11] P. Liu and Y. Wang, "Interval neutrosophic prioritized OWA operator and its application to multiple attribute decision making," Journal of Systems Science and Complexity, vol. 29, no. 3, pp. 681-697, 2016.

[12] D. Yu and S. Shi, "Researching the development of Atanassov intuitionistic fuzzy set: using a citation network analysis," Applied Soft Computing Journal, vol. 32, pp. 189-198, 2015.

[13] D. Yu, W. Zhang, and G. Huang, "Dual hesitant fuzzy aggregation operators," Technological and Economic Development of Economy, vol. 22, no. 2, pp. 194-209, 2016.

[14] A. Skowron, "Rough set rudiments," Help, 2000.

[15] Y. Yao, C.-J. Liau, and N. Zhong, "Granular computing based on rough sets, quotient space theory, and belief functions," in Foundations of Intelligent Systems, N. Zhong, Z. W. Raś, S. Tsumoto, and E. Suzuki, Eds., vol. 2871 of Lecture Notes in Computer Science, pp. 152-159, Springer, Berlin, Germany, 2003.

[16] Z. Pawlak and A. Skowron, "Rudiments of rough sets," Information Sciences, vol. 177, no. 1, pp. 3-27, 2007.

[17] D. Chen, S. Ni, C. Xu, H. Lv, and K. Qin, "A soft rough-fuzzy preference set-based evaluation method for high-speed train operation diagrams," Mathematical Problems in Engineering, vol. 2016, Article ID 5795604, 8 pages, 2016.

[18] B. Liu, Uncertainty Theory, vol. 43 of Studies in Computational Intelligence, Springer, 2010.

[19] P. Liu, X. Zhang, and F. Jin, "A multi-attribute group decisionmaking method based on interval-valued trapezoidal fuzzy numbers hybrid harmonic averaging operators," Journal of Intelligent \& Fuzzy Systems, vol. 23, no. 5, pp. 159-168, 2012.

[20] Y. Deng, "A threat assessment model under uncertain environment," Mathematical Problems in Engineering, vol. 2015, Article ID 878024, 12 pages, 2015.

[21] A. P. Dempster, "Upper and lower probabilities induced by a multivalued mapping," Annals of Mathematical Statistics, vol. 38, pp. 325-339, 1967.

[22] G. Shafer, "A mathematical theory of evidence," in A Mathematical Theory of Evidence, vol. 20, p. 242, Princeton University Press, Princeton, NJ, USA, 1976.

[23] W. Jiang, J. Zhan, D. Zhou, and X. Li, "A method to determine generalized basic probability assignment in the open world," Mathematical Problems in Engineering, vol. 2016, Article ID 3878634, 11 pages, 2016.

[24] M. S. Memon, Y. H. Lee, and S. I. Mari, “Group multi-criteria supplier selection using combined grey systems theory and uncertainty theory," Expert Systems with Applications, vol. 42, no. 21, pp. 7951-7959, 2015.

[25] P. Liu and F. Jin, "A multi-attribute group decision-making method based on weighted geometric aggregation operators of interval-valued trapezoidal fuzzy numbers," Applied Mathematical Modelling, vol. 36, no. 6, pp. 2498-2509, 2012.

[26] P. Liu, F. Jin, X. Zhang, Y. Su, and M. Wang, "Research on the multi-attribute decision-making under risk with interval probability based on prospect theory and the uncertain linguistic variables," Knowledge-Based Systems, vol. 24, no. 4, pp. 554-561, 2011.

[27] A. Neshat and B. Pradhan, "Risk assessment of groundwater pollution with a new methodological framework: application of Dempster-Shafer theory and GIS," Natural Hazards, vol. 78, no. 3, pp. 1565-1585, 2015.

[28] D. Yu, "Intuitionistic fuzzy theory based typhoon disaster evaluation in Zhejiang Province, China: a comparative perspective," Natural Hazards, vol. 75, no. 3, pp. 2559-2576, 2015.

[29] W. Jiang, C. Xie, B. Wei, and D. Zhou, "A modified method for risk evaluation in failure modes and effects analysis of aircraft 
turbine rotor blades," Advances in Mechanical Engineering, vol. 8, no. 4, pp. 1-16, 2016.

[30] D. Yu, "Intuitionistic fuzzy information aggregation under confidence levels," Applied Soft Computing, vol. 19, pp. 147-160, 2014.

[31] P. Liu and Y. Wang, "Multiple attribute decision-making method based on single-valued neutrosophic normalized weighted Bonferroni mean," Neural Computing \& Applications, vol. 25, no. 7-8, pp. 2001-2010, 2014.

[32] R. R. Yager and N. Alajlan, "Decision making with ordinal payoffs under Dempster-Shafer type uncertainty," International Journal of Intelligent Systems, vol. 28, no. 11, pp. 1039-1053, 2013.

[33] Y. Deng, "Generalized evidence theory," Applied Intelligence, vol. 43, no. 3, pp. 530-543, 2015.

[34] G. Campanella and R. A. Ribeiro, "A framework for dynamic multiple-criteria decision making," Decision Support Systems, vol. 52, no. 1, pp. 52-60, 2011.

[35] M. Tabassian, R. Ghaderi, and R. Ebrahimpour, "Knitted fabric defect classification for uncertain labels based on DempsterShafer theory of evidence," Expert Systems with Applications, vol. 38, no. 5, pp. 5259-5267, 2011.

[36] Z.-G. Su and P.-H. Wang, "Minimizing neighborhood evidential decision error for feature evaluation and selection based on evidence theory," Expert Systems with Applications, vol. 39, no. 1, pp. 527-540, 2012.

[37] D. Wei, X. Deng, X. Zhang, Y. Deng, and S. Mahadevan, "Identifying influential nodes in weighted networks based on evidence theory," Physica A: Statistical Mechanics and Its Applications, vol. 392, no. 10, pp. 2564-2575, 2013.

[38] C. Moreira and A. Wichert, "Finding academic experts on a multisensor approach using Shannon's entropy," Expert Systems with Applications, vol. 40, no. 14, pp. 5740-5754, 2013.

[39] P. Liu and Y. Liu, "An approach to multiple attribute group decision making based on intuitionistic trapezoidal fuzzy power generalized aggregation operator," International Journal of Computational Intelligence Systems, vol. 7, no. 2, pp. 291-304, 2014.

[40] C. Yu, J. Yang, D. Yang, X. Ma, and H. Min, "An improved conflicting evidence combination approach based on a new supporting probability distance," Expert Systems with Applications, vol. 42, no. 12, pp. 5139-5149, 2015.

[41] Y. Deng, Y. Liu, and D. Zhou, "An improved genetic algorithm with initial population strategy for symmetric TSP," Mathematical Problems in Engineering, vol. 2015, Article ID 212794, 6 pages, 2015.

[42] A. Mardani, A. Jusoh, and E. K. Zavadskas, "Fuzzy multiple criteria decision-making techniques and applicationstwo decades review from 1994 to 2014," Expert Systems with Applications, vol. 42, no. 8, pp. 4126-4148, 2015.

[43] W. Jiang, B. Wei, C. Xie, and D. Zhou, "An evidential sensor fusion method in fault diagnosis," Advances in Mechanical Engineering, vol. 8, no. 3, pp. 1-7, 2016.

[44] P. Liu, L. He, and X. Yu, "Generalized hybrid aggregation operators based on the 2-dimension uncertain linguistic information for multiple attribute group decision making," Group Decision \& Negotiation, vol. 25, no. 1, pp. 103-126, 2016.

[45] L. A. Zadeh, "Simple view of the dempster-shafer theory of evidence and its implication for the rule of combination," $A I$ Magazine, vol. 7, no. 2, pp. 85-90, 1986.

[46] R. R. Yager, "On the Dempster-Shafer framework and new combination rules," Information Sciences, vol. 41, no. 2, pp. 93137, 1987.
[47] Y. Deng, "D numbers: theory and applications," Journal of Information \& Computational Science, vol. 9, no. 9, pp. 24212428, 2012.

[48] X. Deng, Y. Hu, Y. Deng, and S. Mahadevan, "Environmental impact assessment based on D numbers," Expert Systems with Applications, vol. 41, no. 2, pp. 635-643, 2014.

[49] H.-C. Liu, J.-X. You, X.-J. Fan, and Q.-L. Lin, "Failure mode and effects analysis using $\mathrm{D}$ numbers and grey relational projection method," Expert Systems with Applications, vol. 41, no. 10, pp. 4670-4679, 2014.

[50] X. Deng, Y. Hu, Y. Deng, and S. Mahadevan, "Supplier selection using AHP methodology extended by D numbers," Expert Systems with Applications, vol. 41, no. 1, pp. 156-167, 2014.

[51] G. Fan, D. Zhong, F. Yan, and P. Yue, "A hybrid fuzzy evaluation method for curtain grouting efficiency assessment based on an AHP method extended by D numbers," Expert Systems with Applications, vol. 44, pp. 289-303, 2016.

[52] Y.-M. Wang, J.-B. Yang, and D.-L. Xu, “Environmental impact assessment using the evidential reasoning approach," European Journal of Operational Research, vol. 174, no. 3, pp. 1885-1913, 2006.

[53] N. Rikhtegar, N. Mansouri, A. A. Oroumieh, A. YazdaniChamzini, E. K. Zavadskas, and S. Kildienè, "Environmental impact assessment based on group decision-making methods in mining projects," Economic Research, vol. 27, no. 1, pp. 378392, 2014.

[54] K.-F. Pun, I.-K. Hui, W. G. Lewis, and H. C. W. Lau, "A multiple-criteria environmental impact assessment for the plastic injection molding process: a methodology," Journal of Cleaner Production, vol. 11, no. 1, pp. 41-49, 2003. 


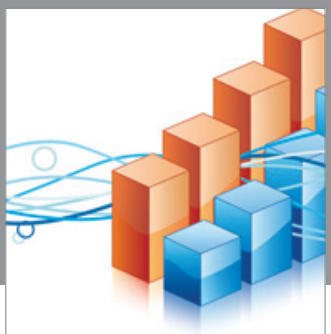

Advances in

Operations Research

vatem alat4

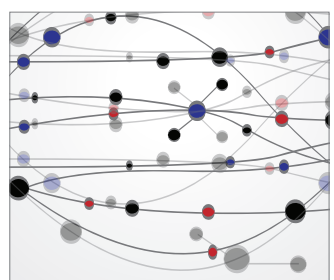

\section{The Scientific} World Journal
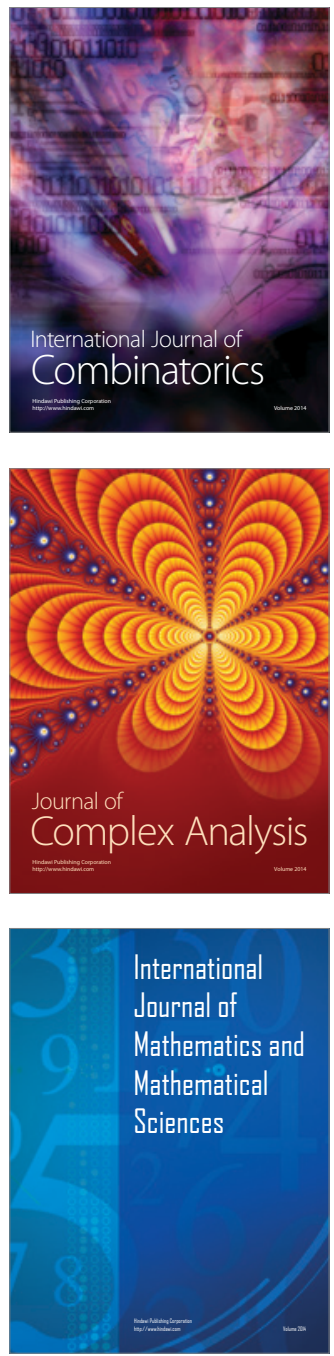
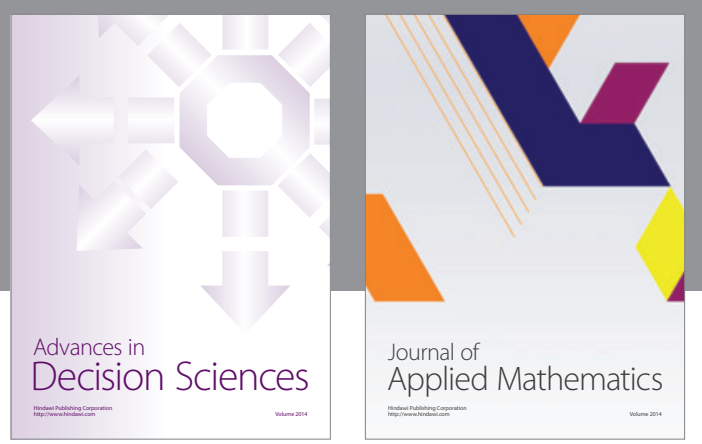

Algebra

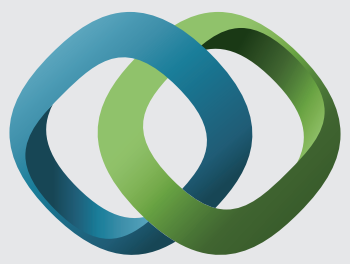

\section{Hindawi}

Submit your manuscripts at

http://www.hindawi.com
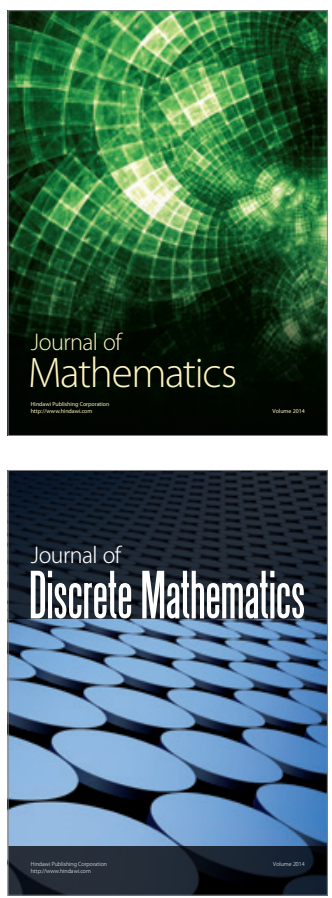

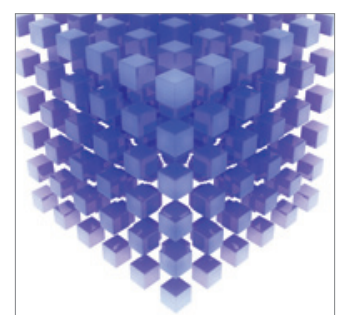

Mathematical Problems in Engineering
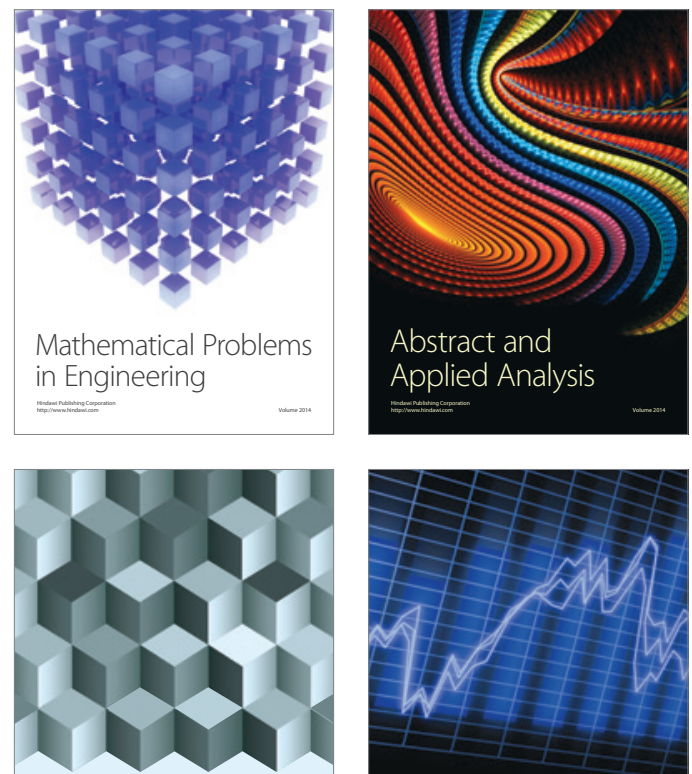

Journal of

Function Spaces

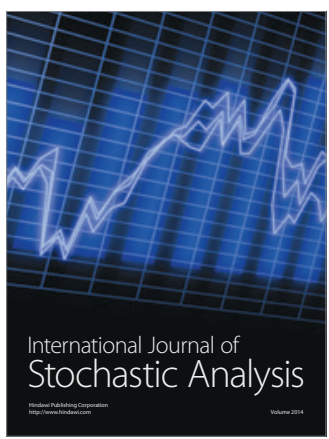

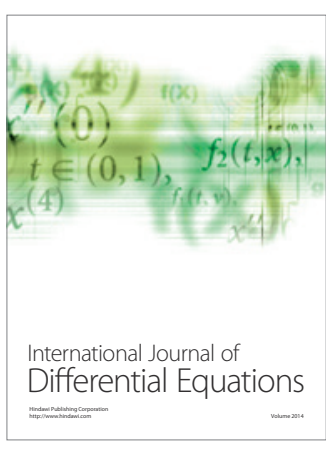
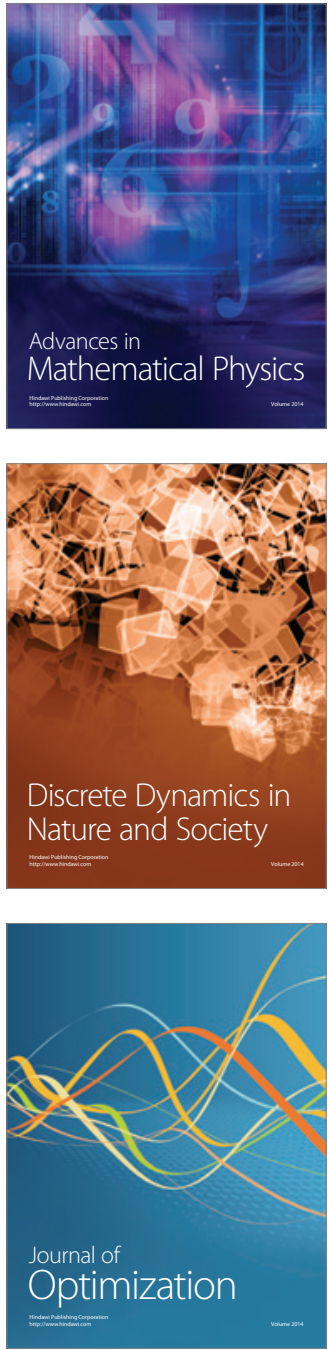